\title{
Fabrication of Ordered Magnetite-Doped Rare Earth Fluoride Nanotube Arrays by Nanocrystal Self-Assembly
}

\author{
Fan Zhang and Dongyuan Zhao ( $\square)$ \\ Shanghai Key Laboratory of Molecular Catalysis and Innovative Materials, Department of Chemistry, and Laboratory of Advanced \\ Materials, Fudan University, Shanghai 200433, China \\ Received: 25 December 2008/Revised: 29 January 2009/Accepted: 30 January 2009 \\ (C) Tsinghua University Press and Springer-Verlag 2009. This article is published with open access at Springerlink.com
}

\begin{abstract}
We describe a nanocrystal self-assembly method for the preparation of rare earth fluoride nanotube (ReFNT) arrays and magnetite-doped rare earth fluoride nanotubes $\left(\mathrm{Fe}_{3} \mathrm{O}_{4}-\mathrm{ReF}-\mathrm{NTs}\right)$ by using porous anodic aluminum oxide (AAO) as a hard template. The ReF-NTs can be simply prepared by the impregnation of $\alpha-\mathrm{NaYF}_{4}$ nanocrystals doped with $\mathrm{Yb}$ and Er into the channels of the porous AAO and show a highly ordered nanotube array and excellent upconversion (UC) fluorescence properties. Similarly, the $\mathrm{Fe}_{3} \mathrm{O}_{4}-\mathrm{ReF}-\mathrm{NTs}$ are obtained by the self-assembly of a mixture of $\mathrm{Fe}_{3} \mathrm{O}_{4}$ and $\mathrm{Yb} / \mathrm{Er}$ doped $\alpha-\mathrm{NaYF}_{4}$ nanocrystals in the AAO pore channels and have a uniform dispersion of magnetite nanocrystals on the rare earth fluoride tube matrix and possess multifunctional magnetic/UC properties. The diameter of these nanotubes can be varied from $60 \mathrm{~nm}$ to several micrometers depending on the pore size of the AAO template. The wall thickness can be increased from 10 to $35 \mathrm{~nm}$ by increasing the concentration of nanocrystals from 0.02 to $0.4 \mathrm{mmol} / \mathrm{L}$, while the morphology of the nanotubes can be varied from small isolated domain structures to percolating domains and eventually to compact domains. A template-directed formation mechanism is proposed and the quantitative predictions of the model for such self-assembled nanocrystal spreading processes are demonstrated. Strong UC fluorescent emissions are realized for the nanotube arrays and multifunctional nanotubes with UC excitation in the near-infrared (NIR) region. A strong magnetic response of the multifunctional nanotubes is observed, which facilitates their easy separation from solution by magnetic decantation using a permanent magnet.
\end{abstract}

\section{KEYWORDS}

Nanotubes, synthesis, nanocrystals, self-assembly, upconversion luminescence, magnetic, rare earth fluorides

\section{Introduction}

One-dimensional (1-D) nanostructures, such as nanowires and nanotubes, are the subject of extensive research in optics, magnetism, and electronics due to their enormous potential as building blocks for nanodevices [1-3]. Among the variety of low-dimensional luminescent nanomaterials studied to date, significant efforts have focused on the wide band gap emission in semiconductor nanostructures [2,3]. Most recently, upconversion (UC) luminescent materials with unique antiStokes optical properties have attracted considerable attention due to their potential uses

Address correspondence to dyzhao@fudan.edu.cn 
in solid-state lasers [4], flat-panel displays [5], solar cells [6], biomolecule detection [7], and opticalfiber-based telecommunications [8]. Up to now, colloidal nanocrystals of UC rare earth fluorides doped with different lanthanides have been obtained through sol-gel, co-precipitation and organometallic thermolysis processes [9-13]. In previous work, we have pioneered the synthesis of ordered short-range rare earth fluoride nanoarrays by hydrothermal methods [14]. We have also obtained ordered 1-D rare earth fluoride UC nanoarrays by using mesoporous silica materials as a hard template [15]. However, the hierarchical design of well defined and highly ordered longrange 3-D arrays of UC 1-D nanomaterials such as nanotubes and nanorods remains a great challenge which must be solved if these materials are to realize their promise in nanodevice applications [16-19]. One recently developed strategy using solution phase nanocrystals as "building blocks" to construct mesoscopic architectures, such as periodic ordered arrays, allowed us to fabricate a variety of organized structures from 1-D nanowires to 2-D and 3-D superlattices or/and arrays [20-22]. Such an approach provides both the possibility to study the collective physical properties resulting from the spatial arrangement of the nanocrystals in the array, such as the dipolar coupling reported in CdSe superlattices [23], and also to exploit the size-tunable optical and electronic properties of nanocrystals in microdevices, such as the proposed single electron tunneling devices [20]. So far, metal, metal oxide, and semiconductor nanocrystals have been shown to selfassemble into ordered structures upon evaporation of the solvent on a 2-D solid substrate or on a water -air interface [20, 22, 24]. However, there have been few reports of the preparation by nanocrystal selfassembly of the type of well defined and ordered oriented 1-D nanotubes, which are much desired for nano-electronic and biological applications. Such nanotubes are different from the single-crystal nanotubes we have previously reported [14, 25], because they can potentially be fabricated by selfassembly of different kinds of nanocrystals,allowing the functional properties of the nanotubes to be tailored according to the target application; as a result,multifunctional nanotubes and nanotube arrays can be obtained.

Here, we report a novel nanocrystal self-assembly approach to prepare ordered 3-D UC nanotube arrays in the pore channels of preparation of anodic aluminum oxide (AAO) templates. Ordered rare earth fluoride (ReF-NT) arrays with excellent UC luminescence have been synthesized via a simple approach involving impregnating nanocrystals of $\alpha-\mathrm{NaYF}_{4}$ doped with $2 \% \mathrm{Er}^{3+}$ and $20 \% \mathrm{Yb}^{3+}$ into a porous AAO membrane. Scanning electron microscopy (SEM) and transmission electron microscopy (TEM) images clearly show that the nanotubes are composed of close-packed uniform nanocrystals and the diameters of the nanotubes can be varied by changing the pore size of the AAO templates. The wall thickness can also be varied by simply increasing the concentration of the nanocrystals. This nanocrystal self-assembly is a general method to construct tubular nanostructures, so that multifunctional magnetite-doped rare earth fluoride nanotubes $\left(\mathrm{Fe}_{3} \mathrm{O}_{4}-\mathrm{ReF}-\mathrm{NTs}\right)$ have also been successfully synthesized by the assembly of $2 \%$ $\mathrm{Tm}^{3+}$ and $20 \% \mathrm{Yb}^{3+}$ doped $\alpha-\mathrm{NaYF}_{4}$ nanocrystals with $\mathrm{Fe}_{3} \mathrm{O}_{4}$ nanocrystals confined in the nanochannels of AAO templates. Similar to ReF-NTs, magnetitedoped $\mathrm{Fe}_{3} \mathrm{O}_{4}-\mathrm{ReF}-\mathrm{NTS}$ show not only ordered arrays, uniform dispersion of $\mathrm{Fe}_{3} \mathrm{O}_{4}$ nanocrystals on the walls, and excellent UC luminescence, but also show strong superparamagnetic properties. Therefore, by combining the attractive tubular structure with UC fluorescent and magnetic properties, the resulting multifunctional nanotubes are ideal candidates for biomedical applications such as bioseparation and targeted drug delivery.

\section{Experimental}

\subsection{Chemicals}

Yttrium nitrate hexahydrate $\left(\mathrm{Y}\left(\mathrm{NO}_{3}\right)_{3} \cdot 6 \mathrm{H}_{2} \mathrm{O}, 99.99 \%\right)$, ytterbium nitrate hexahydrate $\left(\mathrm{Yb}\left(\mathrm{NO}_{3}\right)_{3} \cdot 6 \mathrm{H}_{2} \mathrm{O}\right.$, $99.99 \%)$, erbium nitrate hexahydrate $\left(\mathrm{Er}\left(\mathrm{NO}_{3}\right)_{3} \cdot 6 \mathrm{H}_{2} \mathrm{O}\right.$, $99.99 \%)$, thulium nitrate hexahydrate $\left(\mathrm{Tm}\left(\mathrm{NO}_{3}\right)_{3} \cdot 6 \mathrm{H}_{2} \mathrm{O}, 99.99 \%\right)$, sodium fluoride $(\mathrm{NaF})$, iron (III) chloride hexahydrate $\left(\mathrm{FeCl}_{3} \cdot 6 \mathrm{H}_{2} \mathrm{O}, 99 \%\right)$, 
and iron (II) chloride tetrahydrate $\left(\mathrm{FeCl}_{2} \cdot 4 \mathrm{H}_{2} \mathrm{O}, 99 \%\right)$ were purchased from Shanghai Chemical Reagents Co. and used without any further purification.

\subsection{Synthesis}

\subsubsection{AAO template}

Porous AAO membranes were prepared using a twostep anodizing process [26-30]. After degreasing in ethanol, high-purity Al foil (99.999\%) was electropolished in a $\mathrm{H}_{3} \mathrm{PO}_{4}-\mathrm{H}_{2} \mathrm{SO}_{4}-\mathrm{H}_{2} \mathrm{O}$ (mass ratio, 40: 40:20) solution for $5 \mathrm{~min}$ to reduce the surface roughness. The resulting $\mathrm{Al}$ sheet was washed with ethanol and distilled water, then mounted on a copper plate to serve as anode for anodization. In the first step, anodization of the $\mathrm{Al}$ sheet was carried out under a constant voltage of $40 \mathrm{~V}$ in $0.3 \mathrm{~mol} / \mathrm{L}$ oxalic acid electrolyte for $6 \mathrm{~h}$ at $17^{\circ} \mathrm{C}$. Prior to the second anodization, the disordered porous alumina layer was first removed in a mixture of $\mathrm{H}_{3} \mathrm{PO}_{4}(7 \mathrm{wt} \%)$ and $\mathrm{Cr}_{2} \mathrm{O}_{3}(1.8 \mathrm{wt} \%)$ at $60{ }^{\circ} \mathrm{C}$ for $3 \mathrm{~h}$. A stepwise voltage reduction technique was then utilized to decrease the thickness of the barrier layer. The resulting AAO membrane was immersed in $5 \mathrm{wt} \%$ aqueous $\mathrm{H}_{3} \mathrm{PO}_{4}$ solution for pore widening and barrier layer dissolution, followed by washing and drying. Finally, the through-hole AAO membrane was detached from the $\mathrm{Al}$ substrate using a saturated $\mathrm{HgCl}_{2}$ solution. With this method, AAO templates with different pore diameters from 50 to $300 \mathrm{~nm}$ were prepared.

\subsubsection{Preparation of rare earth fluoride nanocrystals}

The rare earth $(\mathrm{Re})$ fluoride nanocrystals were hydrothermally prepared by using oleic acid as a stabilizing agent, and $\mathrm{NaF}$ and $\operatorname{Re}\left(\mathrm{NO}_{3}\right)_{3}$ as precursors at $130{ }^{\circ} \mathrm{C}$ [14]. In a typical synthesis of cubic phase $\alpha-\mathrm{NaYF}_{4}$ doped with $20 \% \mathrm{Yb}^{3+}$ and $2 \%$ $\mathrm{Er}^{3+}, 0.7 \mathrm{~g}(17.5 \mathrm{mmol})$ of $\mathrm{NaOH}, 7.1 \mathrm{~g}(22.6 \mathrm{mmol})$ of oleic acid (90 wt\%), and $10.0 \mathrm{~g}$ of ethanol were well mixed at room temperature to give a white viscous solution. Then, $8.3 \mathrm{~mL}(4.80 \mathrm{mmol})$ of $0.58 \mathrm{~mol} / \mathrm{L}$ $\mathrm{NaF}$ solution was added with vigorous stirring until a translucent solution was obtained. Then, $1.1 \mathrm{~mL}$ $(0.88 \mathrm{mmol})$ of $0.80 \mathrm{~mol} / \mathrm{L} \mathrm{Y}\left(\mathrm{NO}_{3}\right)_{3}, 0.35 \mathrm{~mL}(0.22$ $\mathrm{mmol})$ of $0.63 \mathrm{~mol} / \mathrm{L} \mathrm{Yb}\left(\mathrm{NO}_{3}\right)_{3}$, and $0.05 \mathrm{~mL}(0.02$ $\mathrm{mmol})$ of $0.40 \mathrm{~mol} / \mathrm{L} \mathrm{Er}\left(\mathrm{NO}_{3}\right)_{3}$ were mixed together and subsequently poured into the above solution with vigorous stirring. After aging for $20 \mathrm{~min}$, the mixture was transferred to a $40 \mathrm{~mL}$ Teflon-lined autoclave, and heated at $130{ }^{\circ} \mathrm{C}$ for $12 \mathrm{~h}$. The system was then allowed to cool to room temperature. The cubic phase $\alpha-\mathrm{NaYF}_{4}: 20 \% \mathrm{Yb}^{3+}, 2 \% \mathrm{Er}^{3+}$ product could be collected from the bottom of the vessel. The cubic phase $\alpha-\mathrm{NaYF}_{4}: 20 \% \mathrm{Yb}^{3+}, 2 \% \mathrm{Tm}^{3+}$ product could also be obtained according to the above method with 1.1 $\mathrm{mL}(0.88 \mathrm{mmol})$ of $0.80 \mathrm{~mol} / \mathrm{L} \mathrm{Y}\left(\mathrm{NO}_{3}\right)_{3}, 0.35 \mathrm{~mL}(0.22$ $\mathrm{mmol})$ of $0.63 \mathrm{~mol} / \mathrm{L} \mathrm{Yb}\left(\mathrm{NO}_{3}\right)_{3}$ and $0.05 \mathrm{~mL}(0.02$ $\mathrm{mmol})$ of $0.40 \mathrm{~mol} / \mathrm{L} \mathrm{Tm}\left(\mathrm{NO}_{3}\right)_{3}$ as reagents.

\subsubsection{Preparation of $\mathrm{Fe}_{3} \mathrm{O}_{4}$ magnetic nanocrystals}

The magnetic $\mathrm{Fe}_{3} \mathrm{O}_{4}$ nanocrystals were hydrothermally prepared at $180{ }^{\circ} \mathrm{C}$ according to a previous report [9]. For a typical preparation, $1.0 \mathrm{~g}(25 \mathrm{mmol})$ of $\mathrm{NaOH}, 10.0 \mathrm{~g}$ (31.8 mmol) of oleic acid (90 wt\%), and $10.0 \mathrm{~g}$ of ethanol were well mixed at room temperature to give a white viscous solution. Then, 10 $\mathrm{mL}$ of a solution containing $2.0 \mathrm{mmol}$ of $\mathrm{FeCl}_{2} \cdot 4 \mathrm{H}_{2} \mathrm{O}$ and $4.0 \mathrm{mmol}$ of $\mathrm{FeCl}_{3} \cdot 6 \mathrm{H}_{2} \mathrm{O}$ was poured into the above solution with vigorous stirring. A virescent precipitate appeared immediately. After stirring for a few minutes, the precipitate turned brown. The mixture was then transferred to a $50 \mathrm{~mL}$ autoclave, sealed, and heated at $180{ }^{\circ} \mathrm{C}$ for $10 \mathrm{~h}$. The system was then allowed to cool to room temperature. The product was deposited at the bottom of the vessel.

\subsubsection{Fabrication of rare earth fluoride nanotube arrays}

The preparation of ordered ReF-NT nanotube arrays was achieved by using a nanocrystal self-assembly approach in the channels of the porous AAO template $[29,30]$. For example (Route 1 in Fig. 1), 4.0 $\mathrm{mL}$ of $0.4 \mathrm{mmol} / \mathrm{L} \alpha-\mathrm{NaYF}_{4}$ nanocrystals doped with $20 \% \mathrm{Yb}^{3+}$ and $2 \% \mathrm{Er}^{3+}$ were transferred into a beaker, and an AAO membrane with pore size of $200 \mathrm{~nm}$ was immersed in this solution. The vessel was sealed with parafilm containing pinholes to allow the solvent to evaporate completely overnight. The resulting dry alumina membranes filled with nanocrystals were aged at $100{ }^{\circ} \mathrm{C}$ for $2 \mathrm{~h}$ in an oven. After the alumina template was completely removed by etching with a $20 \mathrm{wt} \%$ aqueous solution of potassium hydroxide at room temperature, the ordered nanoarrays were recovered after washing with distilled water. 


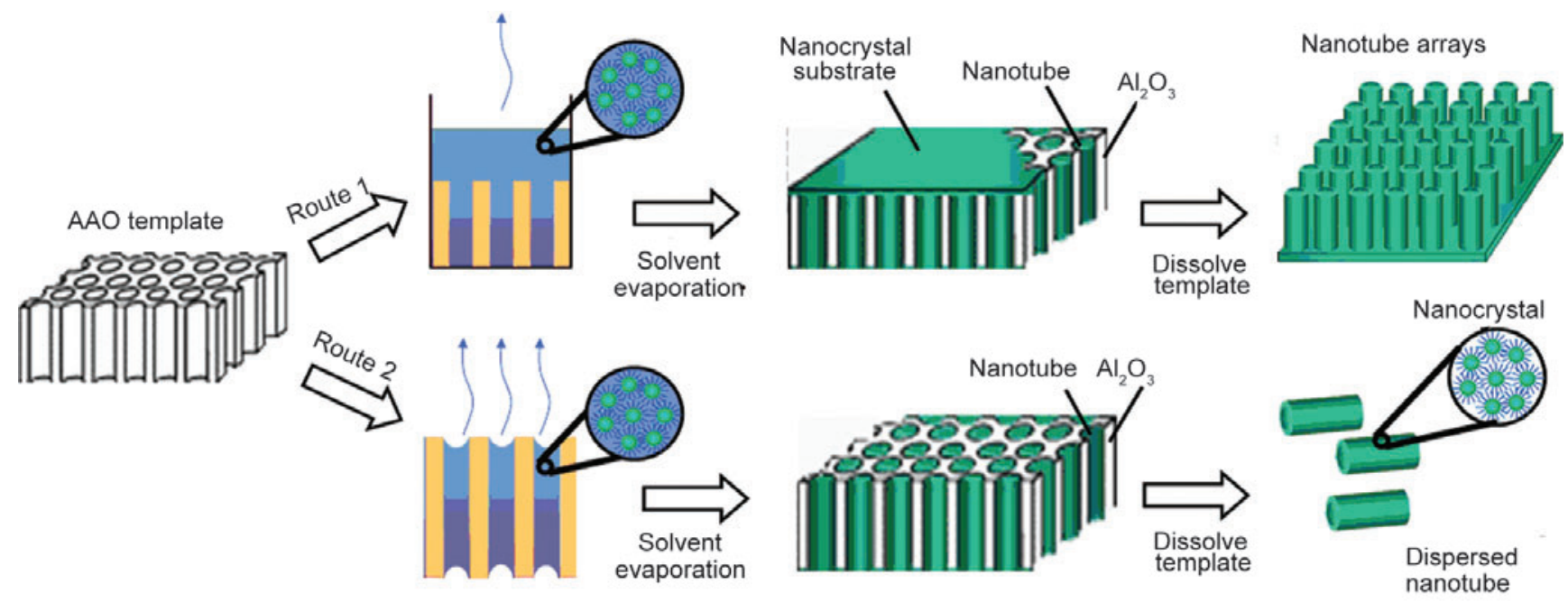

Figure 1 Procedure for the preparation of ordered rare earth fluoride nanotubes (ReF-NTs) (Route 1) and uniform dispersed magnetite-doped rare earth fluoride nanotubes ( $\mathrm{Fe}_{3} \mathrm{O}_{4}-\mathrm{ReF}-\mathrm{NTS}$ ) (Route 2 ) using $\mathrm{AAO}$ membranes as a template

\subsubsection{Fabrication of magnetite-doped rare earth fluoride nanotubes}

For the preparation of dispersed magnetite-doped rare earth fluoride nanotubes $\left(\mathrm{Fe}_{3} \mathrm{O}_{4}-\mathrm{ReF}-\mathrm{NTs}\right)$ (Route 2 in Fig. 1), the AAO membrane was immersed in a sealed beaker containing a solution of lanthanidedoped $\alpha-\mathrm{NaYF}_{4}(0.05 \mathrm{~mol} / \mathrm{L})$ and $\mathrm{Fe}_{3} \mathrm{O}_{4}(0.05 \mathrm{~mol} / \mathrm{L})$ nanocrystals and maintained for $12 \mathrm{~h}$ to ensure complete infiltration of the nanocrystals into the AAO nanochannels. The alumina membrane filled with nanocrystals was then removed from the solution and dried in air for $2 \mathrm{~h}$, followed by aging at $100{ }^{\circ} \mathrm{C}$ for 2 h. After the AAO template was completely removed with a $20 \mathrm{wt} \%$ aqueous solution of potassium hydroxide at room temperature, the $\mathrm{Fe}_{3} \mathrm{O}_{4}-\mathrm{ReF}-\mathrm{NTs}$ were obtained after washing with distilled water.

\subsection{Characterization}

X-ray diffraction (XRD) patterns were recorded with a Bruker D4 diffractometer using $\mathrm{Cu} \mathrm{K} \alpha$ radiation with $40 \mathrm{~mA}$ and $40 \mathrm{kV}$. SEM images were obtained on a Philips XL30 microscope. A thin gold film was sprayed on the samples before characterization. TEM measurements were carried out on a JEOL 2011 microscope operated at $200 \mathrm{kV}$. The samples were dispersed in hexane and then coated on carboncoated copper grids. Fourier transform infrared (FT-IR) spectra were recorded on a Nicolet Fourier spectrophotometer, using $\mathrm{KBr}$ pellets of the solid samples. Upconversion (UC) luminescent spectra were measured on an optical spectrum analyzer (Ando AQ6317, Japan). The sample was put in a cuvette with path length of $1.0 \mathrm{~cm}$ and excited by a $978 \mathrm{~nm}$ NIR excitation (CW) semiconductor diode laser $\left(P_{\max }=800 \mathrm{~mW}\right.$ at $\left.1000 \mathrm{~mA}\right)$. The UC luminescence was collected by a multimode optical fiber with $0.6 \mathrm{~mm}$ core diameter that conducted the luminescence into the optical spectrum analyzer. The distance between the top of the fiber and the sample was about $2 \mathrm{~mm}$.

\section{Results and discussion}

\subsection{Morphology, structure, and composition}

SEM images of the ReF-NTs, prepared by the nanocrystal self-assembly method using the porous AAO membrane as a hard template, show wellaligned nanotubes grown in a perpendicular fashion onto the substrate and arranged in ordered arrays in a very large domain (Fig. 2). Cross-sectional views show that after removal of the AAO template the ReF-NTs grow nearly vertically and penetrate a thin layer of substrate with long-range ordered arrays (Figs. 2(a) and 2(b)). The thickness of the substrate layer composed of the rare earth fluoride 

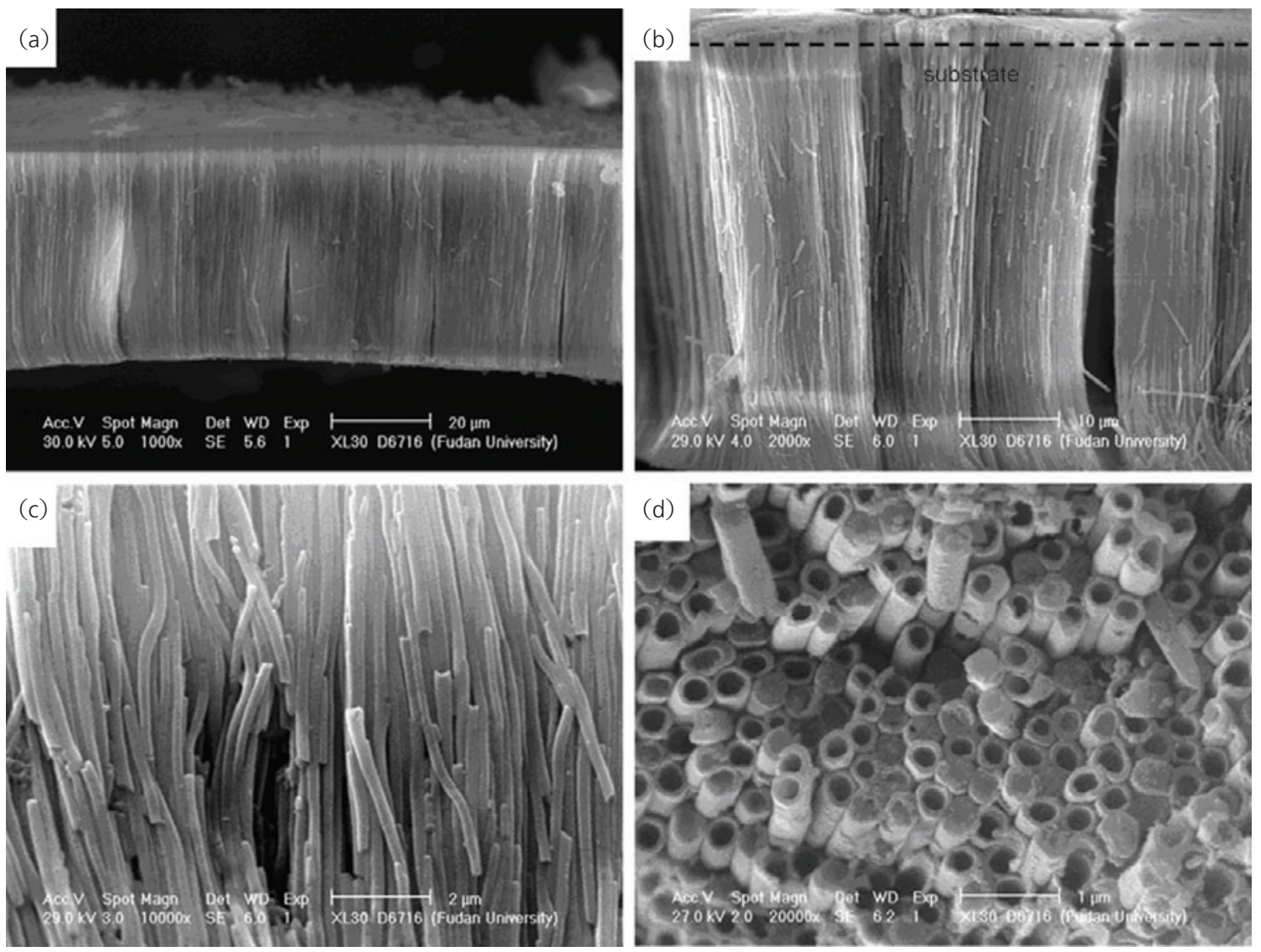

Figure 2 (a), (b) SEM images of well-aligned rare earth fluoride nanotubes with a typical diameter of $200 \mathrm{~nm}$ grown in a perpendicular fashion on the substrate and arranged in uniform arrays; (c) a magnified cross-sectional SEM image of the nanotube arrays after removing the AAO template; (d) bottom view SEM image showing the nanotubes oriented in a perpendicular fashion on the substrate and arranged in a large domain

nanocrystals $\left(\alpha-\mathrm{NaYF}_{4}: 20 \% \mathrm{Yb}^{3+}, 2 \% \mathrm{Er}^{3+}\right)$ is about $800 \mathrm{~nm}$. A magnified side view of the SEM image shows an array of aligned nanotubes with smooth outer surfaces (Fig. 2(c)). A bottom view of the SEM image clearly shows that the nanotubes are oriented in a perpendicular fashion on the substrate (Fig. 2(d)). For the AAO membranes used here, the frequency distribution of pore mouth diameters (total count $=100$ ) is estimated from the SEM images to be $210 \mathrm{~nm} \pm 26 \mathrm{~nm}$. The external diameter of the nanotubes is $228 \mathrm{~nm} \pm 21 \mathrm{~nm}$, indicating some correlation between the critical dimensions of template and nanotubes. However, a slight increase of the nanotube diameter relative to the template pore mouth is observed after removing the template; a similar phenomenon was also reported in a previous paper [29]. In addition, a wall thickness of $35 \mathrm{~nm} \pm 6$ $\mathrm{nm}$ is also obtained by statistical analysis of the SEM images.

TEM images show that the nanotubes are composed of rare earth fluoride nanocrystals (Figs. $3(\mathrm{a})$ and $3(\mathrm{~b})$ ). The particles with diameter $\sim 5 \mathrm{~nm}$ are close packed and form a superlattice (Fig. 3(b)). A high-resolution TEM (HRTEM) image clearly reveals the atomic lattice fringes of the rare earth fluoride nanocrystals, suggesting the nanotubes are crystalline (Fig. 3(c)). To probe the local chemical composition of the nanotube walls, we recorded energy dispersive X-rays (EDX) spectra on the framework at multiple points (Fig. 3(a), inset). The measurements unambiguously reveal that the composition of the products is lanthanide-doped $\mathrm{NaYF}_{4}$ with molar ratios of $\mathrm{Na} / \mathrm{Y}+\mathrm{Yb} / \mathrm{F} \approx 1.0 / 1.0 / 4.0$, further confirming the formation of doped $\mathrm{NaYF}_{4}$. XRD patterns show well-resolved diffraction peaks consistent with high crystallinity (Fig. 3(d)), 

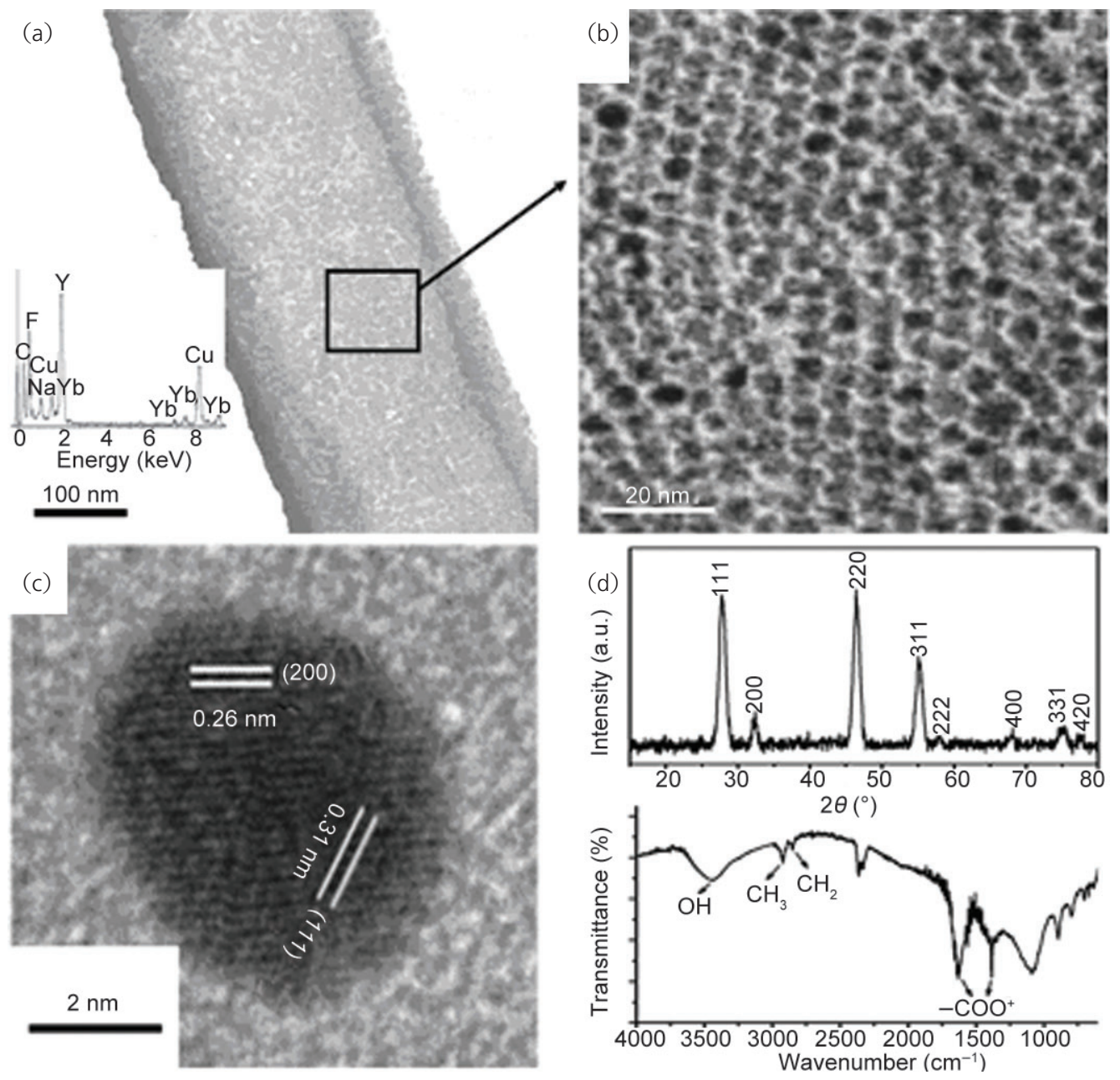

Figure 3 (a) TEM images of the rare earth fluoride nanotubes prepared by the nanocrystal assembly method at $100{ }^{\circ} \mathrm{C}$ for $2 \mathrm{~h}$. The inset image shows the EDX spectrum of the nanotube walls, with the copper signals arising from the TEM grid. (b) A magnified TEM image, showing that the nanocrystals with a diameter of $5 \mathrm{~nm}$ are close packed and form a superlattice. (c) HRTEM image of an individual $\mathrm{NaYF}_{4}$ nanocrystal having a truncated octahedron shape enclosed by the (111) and (200) planes. (d) XRD pattern of the nanotubes constructed from $\alpha$ $-\mathrm{NaYF}_{4}$ nanocrystals. (e) FT-IR spectrum of the nanotubes (ReF-NTs)

which can be indexed to cubic $\alpha-\mathrm{NaYF}_{4}$ with lattice parameter $a=0.547 \AA$ (JCPDS 77-2042; Fm $\overline{3} m$ ). The broadening of the diffraction peaks reveals the nanocrystalline nature of the sample. FT-IR spectroscopy revealed the presence of an organic substance. A broad band at $3100-3620 \mathrm{~cm}^{-1}$ which can be ascribed to $\mathrm{O}-\mathrm{H}$ vibrations is observed (Fig. 3(e)) and the sharp bands at 2923 and $2854 \mathrm{~cm}^{-1}$ can be assigned, respectively, to asymmetric methyl $\left(-\mathrm{CH}_{3}\right)$ stretching and asymmetric and symmetric methylene $\left(-\mathrm{CH}_{2}-\right)$ stretching vibrations in a long alkyl chain; these data suggest that the nanotubes contain oleate moieties. The bands at 1562 and 1445 $\mathrm{cm}^{-1}$ can be assigned to asymmetric and symmetric $\mathrm{COO}^{-}$stretching vibrations, further suggesting that the oleate chains are attached in a bidentate fashion, with both oxygen atoms symmetrically coordinated to the surface.

\subsection{Template synthesis of magnetite-doped nanotubes $\mathrm{Fe}_{3} \mathrm{O}_{4}-\mathrm{ReF}-\mathrm{NTs}$}

Uniform dispersed nanotubes consisting of $\alpha$ $\mathrm{NaYF}_{4}: 20 \% \quad \mathrm{Yb}^{3+} / 2 \% \quad \mathrm{Er}^{3+}$ and $\mathrm{Fe}_{3} \mathrm{O}_{4}$ magnetic nanocrystals $\left(\mathrm{Fe}_{3} \mathrm{O}_{4}-\mathrm{ReF}-\mathrm{NTs}\right)$ can be obtained when the AAO membrane is immersed into a sealed vessel containing a mixed solution of rare earth fluoride

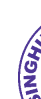

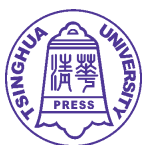

黛 Springer 
and magnetite nanocrystals for a long time without excess solvent (Fig. 1 Route 2). The SEM image shows that dispersed uniform nanotubes are obtained after removing the alumina template (Fig. 4(a)). EDX spectra clearly reveal the absence of aluminium and that the nanotubes contain $\mathrm{Y}, \mathrm{Yb}$, and Fe (Fig. 4(a) inset), suggesting that the nanotubes are composed of $\mathrm{Yb}^{3+} / \mathrm{Er}^{3+}$ doped $\alpha-\mathrm{NaYF}_{4}$ doped with $\mathrm{Fe}_{3} \mathrm{O}_{4}$. The well-resolved XRD patterns (Fig. 4(b)) can be indexed to a mixture of cubic $\mathrm{NaYF}_{4}$ with lattice parameter $a=0.547 \mathrm{~nm}$ (JCPDS 77-2042; $F m \overline{3} m$ ) and magnetite $\mathrm{Fe}_{3} \mathrm{O}_{4}$ with lattice parameter $a=0.840 \mathrm{~nm}$ (JCPDS 76-1849; Fd $\overline{3} m$ ), and are indicative of high crystallinity. The HRTEM image shows that both the lanthanide-doped $\alpha-\mathrm{NaYF}_{4}$ and $\mathrm{Fe}_{3} \mathrm{O}_{4}$ nanocrystals are encapsulated into the nanotube walls according to the respective atomic lattice fringes (Fig. 4(c)).

\subsection{Size and wall thickness}

The diameter of the nanotubes can be controlled over a broad range from $60 \mathrm{~nm}$ to several micrometers, depending on the pore diameter of the AAO template. For example, uniform $\left(\alpha-\mathrm{NaYF}_{4}: 20 \%\right.$ $\left.\mathrm{Yb}^{3+} / 2 \% \mathrm{Er}^{3+}\right)$ and $\mathrm{Fe}_{3} \mathrm{O}_{4}$ nanotubes with a diameter of $60 \mathrm{~nm}$ can be obtained by annealing an impregnanted AAO template with a small pore diameter of 50 nm (Fig. 4(d)). The wall thickness of the nanotubes can be tuned by varying the concentration of the nanocrystals. When the nanocrystal concentration is $0.02 \mathrm{mmol} / \mathrm{L}$, nanotubes with many holes are formed
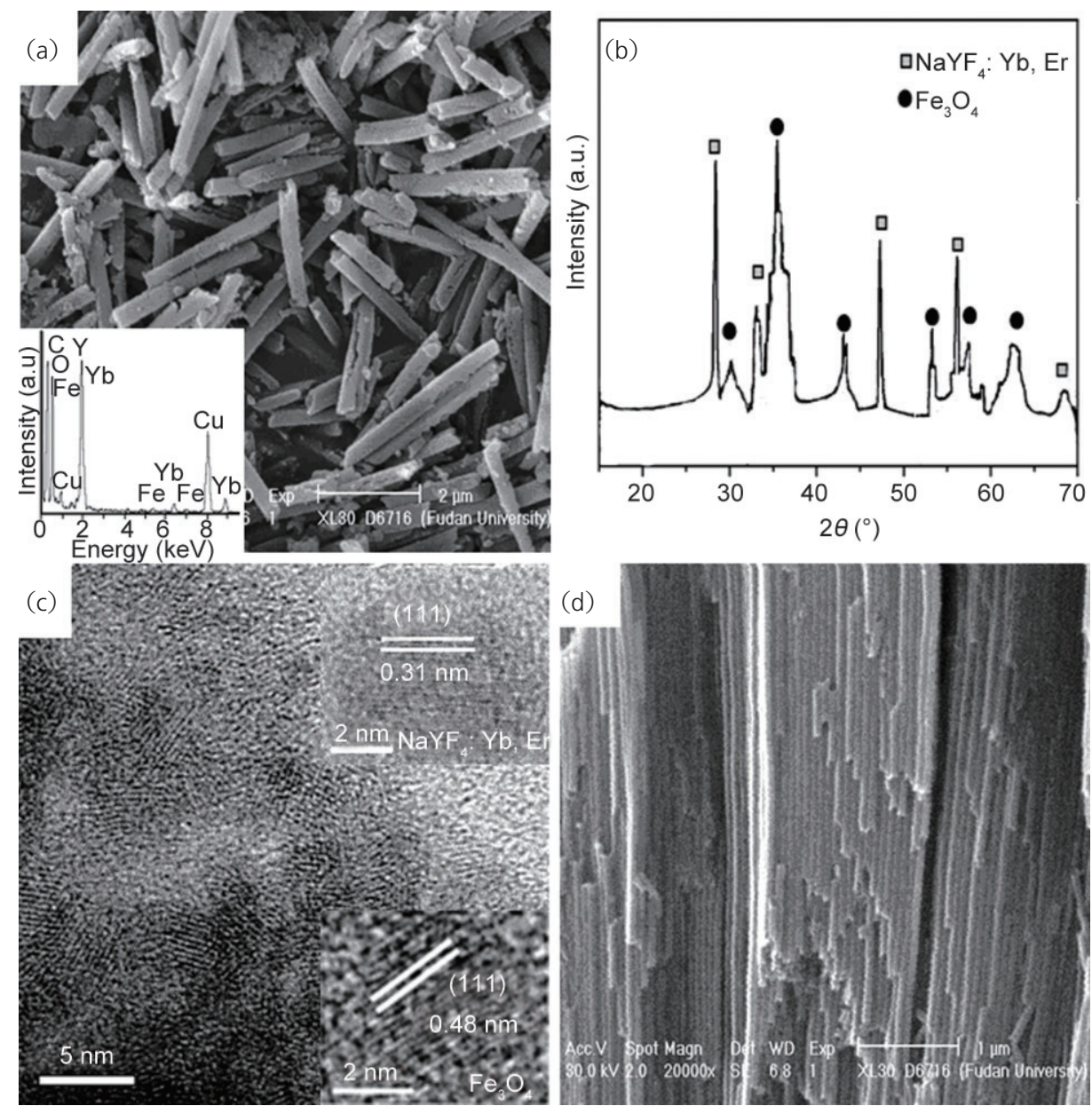

Figure 4 (a) SEM image of magnetite-doped rare earth fluoride nanotubes $\left(\mathrm{Fe}_{3} \mathrm{O}_{4}-\mathrm{ReF}-\mathrm{NTS}\right)$ consisting of $\alpha-\mathrm{NaYF}_{4}: 20 \% \mathrm{Yb}^{3+} / 2 \% \mathrm{Er}^{3+}$ and $\mathrm{Fe}_{3} \mathrm{O}_{4}$ nanocrystals. The inset image shows the EDX spectrum of the nanotube wall, with the copper signals arising from the TEM grid; (b) XRD pattern of the $\mathrm{Fe}_{3} \mathrm{O}_{4}-$ ReF-NTs; (c) HRTEM image of the $\mathrm{Fe}_{3} \mathrm{O}_{4}-$ ReF-NTs; (d) SEM image of well-aligned $\mathrm{Fe}_{3} \mathrm{O}_{4}-$ ReF-NT arrays with a typical diameter of $60 \mathrm{~nm}$ oriented in a perpendicular fashion to the substrate and arranged in a large domain 
and the wall thickness is about $10 \mathrm{~nm}$. When the concentration is increased to 0.1 and $0.2 \mathrm{mmol} / \mathrm{L}$, the holes in the nanotubes gradually disappear and the wall thickness increases to 15 and $25 \mathrm{~nm}$, respectively (Fig. 5). The thickness of the ReF-NT substrate can also be tuned by varying the concentration of nanocrystals. The thickness of the substrate increases from 150, 300, 400 to $800 \mathrm{~nm}$ by increasing the nanocrystal concentration from $0.02,0.1,0.2$ to 0.4 $\mathrm{mmol} / \mathrm{L}$, respectively. Furthermore, nanotubes with smooth surfaces are obtained when the concentration is increased to $0.4 \mathrm{mmol} / \mathrm{L}$ and the wall thickness increases to $35 \mathrm{~nm}$ (Fig. 5). With increasing thickness, the wall morphology changes from small isolated domains to percolating domains and eventually to compact domains with smooth surfaces (Fig. 5). These structures have been frequently observed for other materials in Refs. [31-34]. Dewetting makes holes open up in the liquid layer and particles move outward, away from the holes, as the solvent evaporates. Only when the interaction between particles and the substrate is sufficiently strong can the nanocrystals be pinned to the substrate. The domain structure is strongly dependent on the nanocrystal concentration. Isolated domains are formed at a low concentration when the pinning effect is weak and dewetting holes percolate across the substrate (Fig. 5). As the concentration increases, the pinning effect becomes stronger because of the enhanced particle-particle interactions. Dewetting holes then become more isolated and percolating particle domains are formed (Fig. 5). At even higher concentrations, the sizes of the dewetting holes decrease significantly and a compact multilayer is formed.

\subsection{Formation mechanism}

A template-directed nanocrystal self-assembly formation process can be proposed for the nanotubes, based on both our results and quantitative predictions by Fitzmaurice and Gennes [33, 35]. In a colloidal suspension, individual nanocrystals may be viewed as analogous to dissolved molecules. As the solvent evaporates from a droplet of such a colloid on a substrate, the solubility limit is exceeded and a superlattice of nanocrystals can nucleate on the surface because of both particle-particle and particle-substrate interactions. The first condition that must be met for a fluid to wet a substrate is that the spreading coefficient $S$ is positive [35]. For the nanocrystal spreading process of interest,

$$
S=\gamma_{\text {sub }}-\left(\gamma_{\text {nan, sub }}+\gamma_{\text {nan, nan }}\right) \text {, }
$$

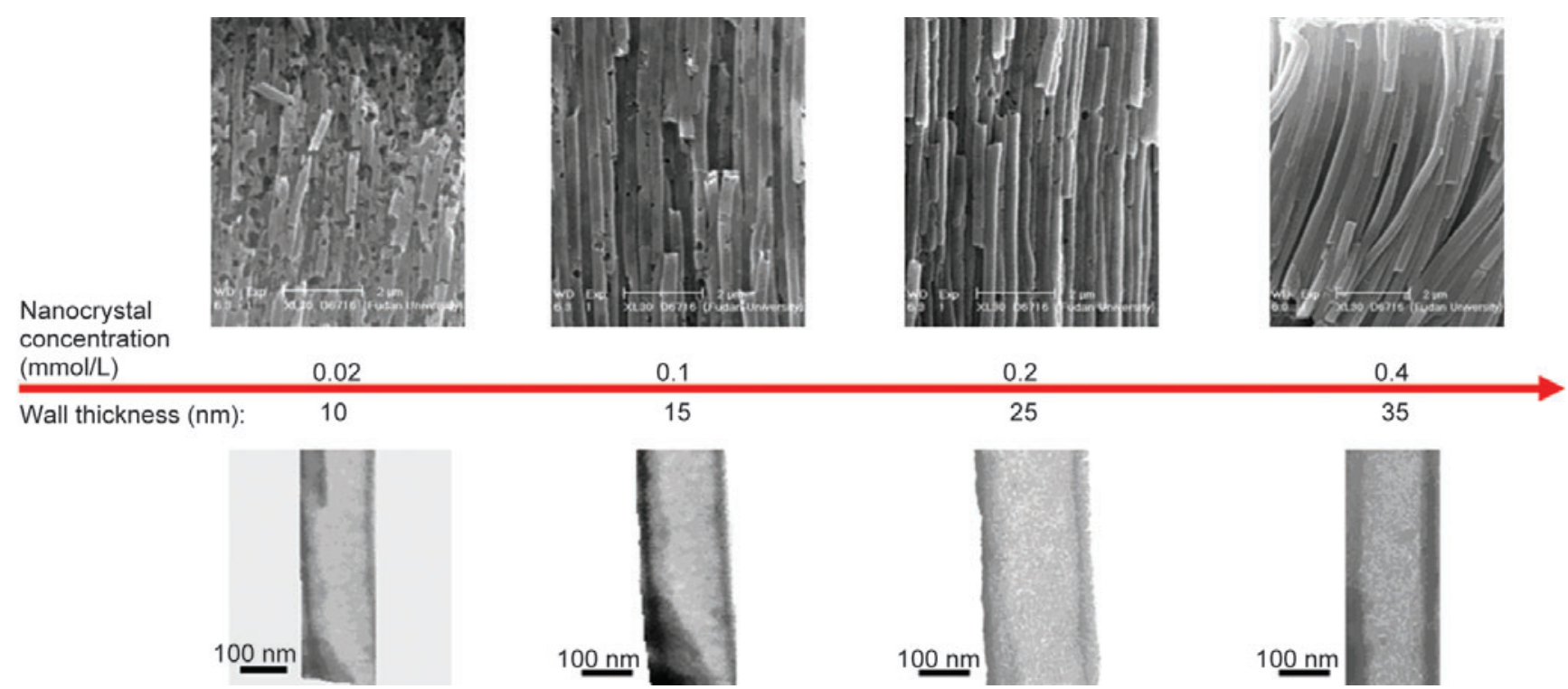

Figure 5 SEM images (top) of the rare earth fluoride nanotubes (ReF-NTs) and TEM images (bottom) of individual nanotubes, showing that the wall thickness increases from 10,15, 25 to $35 \mathrm{~nm}$ with the increase of the nanocrystal concentration from $0.02,0.1,0.2$ to $0.4 \mathrm{mmol} / \mathrm{L}$, while the morphology changes from small isolated structures $(0.02 \mathrm{mmol} / \mathrm{L})$ to percolating domains $(0.2$ and $0.3 \mathrm{mmol} / \mathrm{L})$ and eventually to compact domains $(0.4 \mathrm{mmol} / \mathrm{L})$ 
where $\gamma_{\text {sub }}, \gamma_{\text {nan, sub}}$, and $\gamma_{\text {nan, nan }}$ are the substratesolvent, nanocrystal-substrate, and nanocrystalnanocrystal surface tensions respectively. These surface tensions are calculated using the YoungDupré relation [36] between the surface tension of two free surfaces and the adhesive energy between the two surfaces in contact:

$$
\gamma_{\text {nan, sub }}=\gamma_{\text {nan }}+\gamma_{\text {sub }}-W_{\text {adh, } \square}
$$

and

$$
\gamma_{\text {nan, nan }}=2 \gamma_{\text {nan }}-W_{\text {coh, } \square}
$$

In Eqs. (2) and (3), $\gamma_{\text {nan }}$ is the surface tension of a free nanocrystal in solution; $W_{\mathrm{adh}, \square}$ is the adhesive work between the nanocrystal and the substrate in contact normalized by the effective cross-sectional area that is occupied by the nanocrystals in the nanotube wall; and $W_{\text {coh, } \square}$ is the corresponding cohesive work between two nanocrystals [33, 37]. Therefore,

$$
S=-3 \gamma_{\text {nan }}+W_{\text {adh, } \square}+W_{\text {coh, } \square} .
$$

The constants $S$ and $\gamma_{\text {nan, nan }}$ can be calculated from $W_{\text {adh, }}, W_{\text {coh, } \square \text {, and }} \gamma_{\text {nan }}$ and depend on the van der Waals attraction in the final dry nanotube wall [37]. Applying the quantitative predictions derived by Fitzmaurice [33] for such selfassembled nanocrystal spreading processes, the two conditions, $S>0$ and $\gamma_{\text {nan, nan }}>0$, must be met for the nanocrystal film to spread on the substrate, and the thickness of the layer is directly related to these parameters.

Nanocrystals capped with organic molecules mostly have low surface energies (the surface tension between the $5 \mathrm{~nm}$ rare earth fluoride nanocrystals is $2.2 \times 10^{-3} \mathrm{dyn} / \mathrm{cm}, 1$ dyn $=10^{-5} \mathrm{~N}$ ), whereas inorganic alumina is a high surface energy material (the surface tension of the AAO interface is $900 \mathrm{dyn} / \mathrm{cm}$ ); therefore, according to Eq. (1) and the quantitative predictions of Fitzmaurice [33], the organic molecule capped nanocrystals are inclined to spread easily on the internal surface of the AAO. On the other hand, the aging treatment at $100{ }^{\circ} \mathrm{C}$ before the AAO template removal is also very important in order to maintain the intact products. There is an underlying driving force due to short-range as well as longrange van der Waals interactions between the oleic acid groups capped on the nanocrystals, which ensures that the tubular structure is retained after the AAO template is completely removed.

\subsection{UC fluorescence}

The visible and NIR UC luminescence spectra of the ReF-NTs containing $\alpha-\mathrm{NaYF}_{4}: 20 \% \mathrm{Yb}^{3+} / 2 \% \mathrm{Er}^{3+}$ and $\alpha-\mathrm{NaYF}_{4}: 20 \% \mathrm{Yb}^{3+} / 2 \% \mathrm{Tm}^{3+}$ nanocrystals under infrared excitation $(978 \mathrm{~nm})$ are shown in Figs. 6(a)
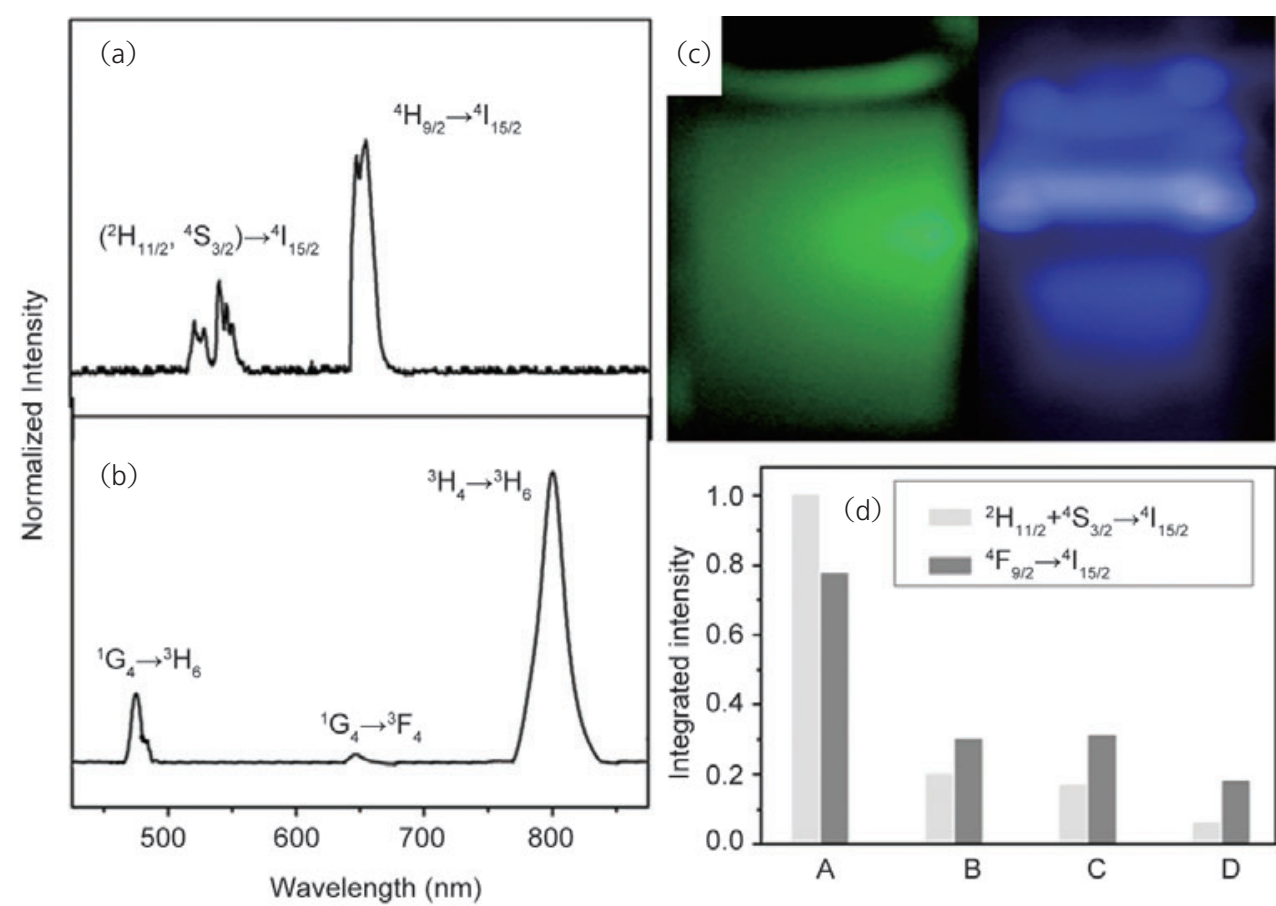

Figure 6 UC luminescence spectra of the rare earth fluoride nanotubes composed of (a) $\alpha-\mathrm{NaYF}_{4}: 20 \%$ $\mathrm{Yb}^{3+} / 2 \% \mathrm{Er}^{3+}$ and (b) $\alpha-\mathrm{NaYF}_{4}: 20 \% \mathrm{Yb}^{3+} / 2 \% \mathrm{Tm}^{3+}$ nanocrystals excited with a $978 \mathrm{~nm}$ laser diode (power density $=80 \mathrm{~W} / \mathrm{cm}^{2}$ ). (c) Photographs of the UC luminescence of the rare earth fluoride nanotubes composed of $\alpha-\mathrm{NaYF}_{4}: 20 \% \mathrm{Yb}^{3+} / 2 \% \mathrm{Er}^{3+}$ (green) and $\alpha-\mathrm{NaYF}_{4}: 20 \% \mathrm{Yb}^{3+} / 2 \% \mathrm{Tm}^{3+}$ (blue) in $1 \mathrm{wt} \%$ hexane solutions, excited with a laser power of $800 \mathrm{~mW}$ at $978 \mathrm{~nm}$. (d) Integrated green $\left({ }^{2} \mathrm{H}_{11,2}+{ }^{4} \mathrm{~S}_{3,2} \rightarrow{ }^{4} \mathrm{I}_{15,2}\right)$ and red $\left({ }^{4} \mathrm{~F}_{9,2} \rightarrow{ }^{4} \mathrm{I}_{15,2}\right)$ UC emission intensity of $(\mathrm{A})$ the bulk sample $\left(\beta-\mathrm{NaYF}_{4}: 20 \% \mathrm{Yb}^{3+} / 2 \% \mathrm{Er}^{3+}\right)$; (B) the rare earth fluoride nanotube arrays composed of $\alpha-\mathrm{NaYF}_{4}: 20 \% \mathrm{Yb}^{3+} / 2 \% \mathrm{Er}^{3+}$ nanocrystals; (C) $\alpha-\mathrm{NaYF}_{4}: 20 \%$ $\mathrm{Yb}^{3+} / 2 \% \mathrm{Er}^{3+}$ nanocrystals; (D) multifunctional magnetite-doped rare earth fluoride nanotubes composed of $\alpha-\mathrm{NaYF}_{4}: 20 \% \mathrm{Yb}^{3+} / 2 \% \mathrm{Er}^{3+}$ and $\mathrm{Fe}_{3} \mathrm{O}_{4}$ nanocrystals 
and $6(\mathrm{~b})$. The emission bands can be assigned to transitions within the $4 \mathrm{f}-4 \mathrm{f}$ levels of the $\mathrm{Er}^{3+}$ and $\mathrm{Tm}^{3+}$ ions [38-40]. In the case of the $\mathrm{Er}^{3+}$-doped sample, green luminescence between 523.5 and 542.5 nm arises from the $\left({ }^{2} \mathrm{H}_{11 / 2}{ }^{4} \mathrm{~S}_{3 / 2}\right) \rightarrow{ }^{4} \mathrm{I}_{15 / 2}$ transition. A dominant red emission is observed between 630 and $680 \mathrm{~nm}$ originating from the ${ }^{4} \mathrm{~F}_{9 / 2} \rightarrow{ }^{4} \mathrm{I}_{15 / 2}$ transition. In the $\mathrm{Tm}^{3+}$-doped sample, the visible luminescence originates from two transitions ${ }^{1} \mathrm{G}_{4} \rightarrow{ }^{3} \mathrm{H}_{6}$ and ${ }^{1} \mathrm{G}_{4} \rightarrow$ ${ }^{3} \mathrm{~F}_{4}$, resulting in a blue emission at $452.5-482 \mathrm{~nm}$ and a weak red one at 630-680 nm. Furthermore, an intense NIR emission is observed at $750-850 \mathrm{~nm}$ due to the ${ }^{3} \mathrm{H}_{4} \rightarrow{ }^{3} \mathrm{H}_{6}$ transition.

The mechanisms responsible for the UC luminescence of the $\mathrm{Er}^{3+} / \mathrm{Yb}^{3+}$ and $\mathrm{Tm}^{3+} / \mathrm{Yb}^{3+}$ ion couples are shown in Fig. 7 [40]. In the $\mathrm{Er}^{3+}$-doped case, the most important excitation path is ${ }^{4} \mathrm{I}_{15 / 2} \rightarrow$ ${ }^{4} \mathrm{H}_{11 / 2} \rightarrow{ }^{4} \mathrm{~F}_{7 / 2}$, which requires two energy transfers from $\mathrm{Yb}^{3+}$. Subsequent multi-phonon relaxation populates the emitting ${ }^{2} \mathrm{H}_{11 / 2}$ and ${ }^{4} \mathrm{~S}_{3 / 2}$ states. At first, an energy transfer from a $\mathrm{Yb}^{3+}$ ion in the ${ }^{2} \mathrm{~F}_{5 / 2}$ state to an $\mathrm{Er}^{3+}$ ion populates the ${ }^{4} \mathrm{I}_{11 / 2}$ level. A second 980 $\mathrm{nm}$ photon, or energy transfer from a $\mathrm{Yb}^{3+}$ ion, can then populate the ${ }^{4} \mathrm{~F}_{7 / 2}$ level of the $\mathrm{Er}^{3+}$ ion. $\mathrm{Er}^{3+}$ ions

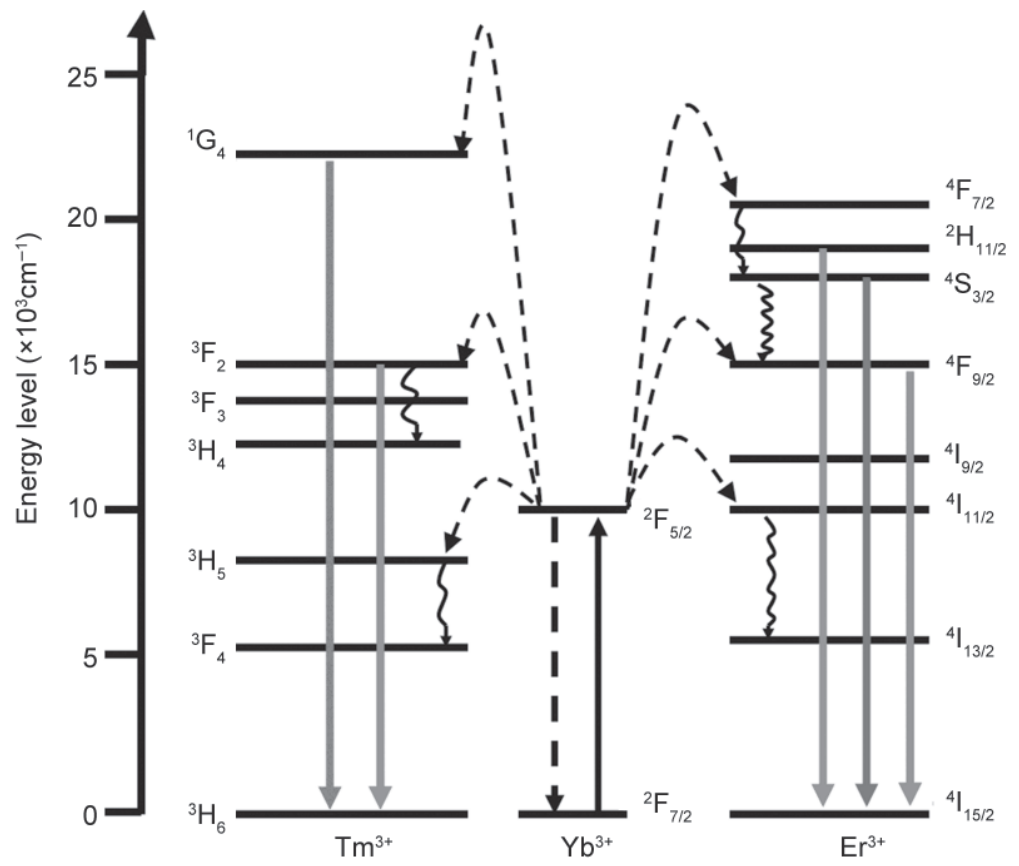

Figure 7 Schematic energy-level diagrams for the $\mathrm{Er}^{3+}, \mathrm{Tm}^{3+}$, and $\mathrm{Yb}^{3+}$ dopant ions and the UC mechanism excited by a $980 \mathrm{~nm}$ laser diode. The solid, dotted, and curly arrows indicate radiative, non-radiative energy transfer, and multi-photon relaxation processes, respectively can then relax nonradiatively (without emission of photons) to ${ }^{2} \mathrm{H}_{11 / 2}$ and ${ }^{4} \mathrm{~S}_{3 / 2}$ levels and the green $\left({ }^{2} \mathrm{H}_{11 / 2}\right.$, $\left.{ }^{4} \mathrm{~S}_{3 / 2}\right) \rightarrow{ }^{4} \mathrm{I}_{15 / 2}$ emissions occur. Alternatively, the ion can further relax and populate the ${ }^{4} \mathrm{~F}_{9 / 2}$ level, leading to the red ${ }^{4} \mathrm{~F}_{9 / 2} \rightarrow{ }^{4} \mathrm{I}_{15 / 2}$ emission. The ${ }^{4} \mathrm{~F}_{9 / 2}$ level may also be populated from the ${ }^{4} \mathrm{I}_{13 / 2}$ level of $\mathrm{Er}^{3+}$ ions by absorption of a $980 \mathrm{~nm}$ photon, or energy transfer from a $\mathrm{Yb}^{3+}$ ion with a ${ }^{4} \mathrm{I}_{13 / 2}$ state and is initially populated via the nonradiative ${ }^{4} \mathrm{I}_{11 / 2} \rightarrow{ }^{4} \mathrm{I}_{13 / 2}$ relaxation. For the $\mathrm{Tm}^{3+} / \mathrm{Yb}^{3+}$ co-doped sample, three subsequent energy transfers from $\mathrm{Yb}^{3+}$ ions populate the upper $\mathrm{Tm}^{3+}$ levels and the various emissions can occur.

As-synthesized $\alpha-\mathrm{NaYF}_{4}: 20 \% \mathrm{Yb}^{3+} / 2 \% \mathrm{Er}^{3+}$ and $\alpha-\mathrm{NaYF}_{4}: 20 \% \mathrm{Yb}^{3+} / 2 \% \mathrm{Tm}^{3+}$ nanotubes are easily dispersed in organic solvents, such as hexane, to form a nearly transparent colloidal solution. Figure 6(c) shows the nanotube colloidal solutions (0.1 wt\%) under $980 \mathrm{~nm} \mathrm{CW}$. The laser power for excitation was $800 \mathrm{~mW}$ with a power density $<0.1 \mathrm{~W} / \mathrm{m}^{2}$. The green light in Fig. 6(c) results from the 523.5 and $542.5 \mathrm{~nm}$ emission of the $\alpha-\mathrm{NaYF}_{4}: 20 \% \mathrm{Yb}^{3+} / 2 \%$ $\mathrm{Er}^{3+}$ nanotubes, whereas the blue light corresponds to the 452.5 and $482 \mathrm{~nm}$ emissions of the $\alpha-\mathrm{NaYF}_{4}: 20 \%$ $\mathrm{Yb}^{3+} / 2 \% \mathrm{Tm}^{3+}$ nanotubes. It should be noted that the NIR emission of $\alpha-\mathrm{NaYF}_{4}: 20 \% \mathrm{Yb}^{3+} / 2 \%$ $\mathrm{Tm}^{3+}$ at $800 \mathrm{~nm}$ is invisible to both the human eye and the camera.

Detailed studies of the multicolor UC fluorescence properties were performed on nanotube samples containing $\mathrm{Yb}^{3+} / \mathrm{Er}^{3+} \mathrm{co}$-doped $\alpha-\mathrm{NaYF_{4 }}$. UC efficiencies of the $\alpha-\mathrm{NaYF}_{4}: \mathrm{Yb}^{3+} / \mathrm{Er}^{3+}$ and magnetite-doped $\alpha-\mathrm{NaYF}_{4}: \mathrm{Yb}^{3+} / \mathrm{Er}^{3+}$ / $\mathrm{Fe}_{3} \mathrm{O}_{4}$ nanotubes, cubic phase $\mathrm{NaYF}_{4}$ : $\mathrm{Yb}^{3+} / \mathrm{Er}^{3+}$ nanocrystals, and $\beta-\mathrm{NaYF}_{4}$ : $\mathrm{Yb}^{3+} / \mathrm{Er}^{3+}$ bulk samples are shown in Fig. 6(d) [14]. Compared with the bulk $\mathrm{Er}^{3+} / \mathrm{Yb}^{3+}$-doped $\beta-\mathrm{NaYF}_{4}$ sample, the $\alpha-\mathrm{NaYF}_{4}: \mathrm{Yb}^{3+} / \mathrm{Er}^{3+}$ nanotubes show a higher emission ratio of red to green photons, probably due to sizedependent nonradiative relaxation. As the particle size decreases, the ratio of surface to volume increases, and the number of surface defects with available large vibrational modes 
such as those of anions increases, resulting in a great increase in nonradiative relaxation [42, 43]. Thus, high efficiencies are observed. Although the nanotube sample has a higher emission ratio of red to green photons than the bulk sample, this ratio is still lower than that for the dispersed $\alpha-\mathrm{NaYF}_{4}$ : $\mathrm{Yb}^{3+} / \mathrm{Er}^{3+}$ nanocrystal colloids. Although the tubes are constructed from the nanocrystals, the surface area is lower than that of the precursor nanocrystal colloids. This suggests that the nonradiative relaxation is related to the surface area. Furthermore, the emission ratio of red to green photons greatly increases for the magnetite-doped nanotubes $\left(\mathrm{Fe}_{3} \mathrm{O}_{4}-\mathrm{ReF}-\mathrm{NTs}\right)$. This can be ascribed to the effect of $\mathrm{O}$ and $\mathrm{Fe}$ on the UC emission population, which has been explained by a cross-relaxation process [15, 43].

\subsection{Magnetic properties}

The magnetic properties of the $\mathrm{Fe}_{3} \mathrm{O}_{4}-\mathrm{ReF}$-NTs composed of $\alpha-\mathrm{NaYF}_{4}: 20 \% \mathrm{Yb}^{3+} / 2 \% \mathrm{Er}^{3+}$ and $\mathrm{Fe}_{3} \mathrm{O}_{4}$ nanocrystals were recorded using a physical properties measurement system (PPMS). The temperature dependence of magnetization was measured at an applied field of 100 Oe between 2 and $350 \mathrm{~K}$ using zero-field-cooling (ZFC) and fieldcooling (FC) procedures. Plots of magnetization versus temperature for the multifunctional nanotubes with ZFC and FC are presented in Fig. 8(a). The curves coincide at high temperatures but diverge at low temperatures, showing a maximum (in the case of the ZFC curve) at $110 \mathrm{~K}\left(T_{\max }\right)$. Such behavior is characteristic of superparamagnetism where there is progressive deblocking of particles as the temperature increases [44]. It is generally assumed that the temperature of the maximum in the ZFC curve depends on the average particle size, while the temperature at which the FC and ZFC curves start to diverge corresponds to the blocking temperature of the largest particles. The blocking temperature $\left(T_{\mathrm{B}}\right)$ of the $\mathrm{Fe}_{3} \mathrm{O}_{4}-\mathrm{ReF}-\mathrm{NTs}$ is $150 \mathrm{~K}$, indicating that nanoparticle aggregates are formed in the nanotubes. The formation of superparamagnetic rather than ferromagnetic nanoparticles is important for practical applications [45]. The hysteresis loops observed at 5 and $300 \mathrm{~K}$ are shown in Fig. 8(b). At $300 \mathrm{~K}$, the magnetite nanoparticles do not display magnetic

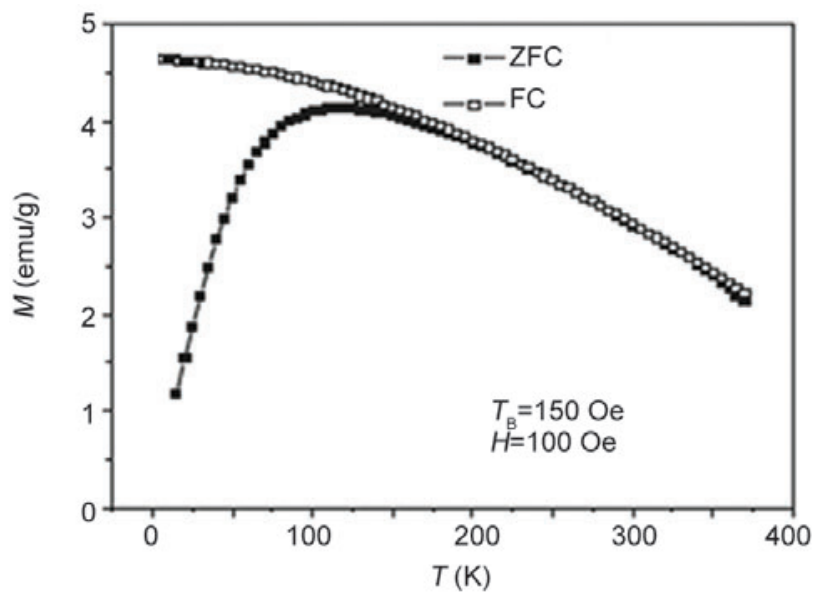

(a)

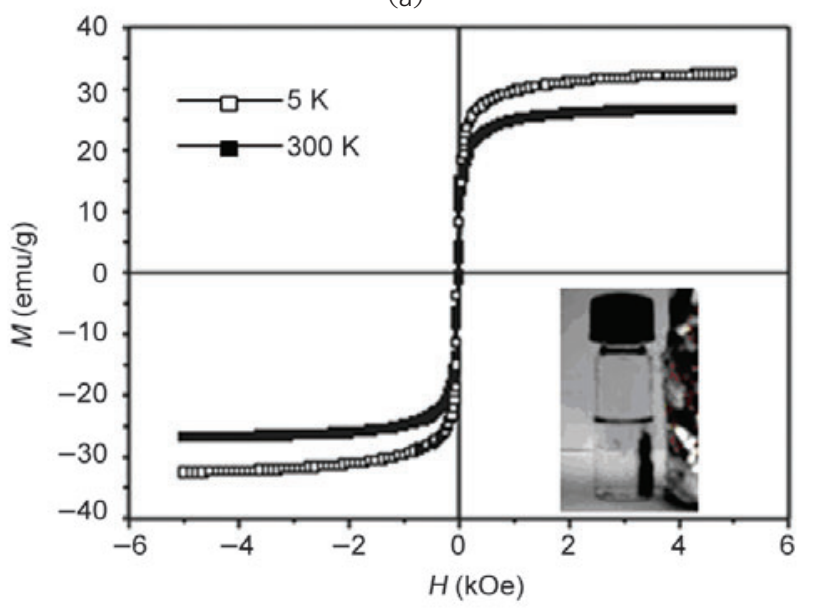

(b)

Figure 8 (a) The temperature dependence of ZFC and FC magnetization curves for the magnetite-doped rare earth fluoride nanotubes ( $\mathrm{Fe}_{3} \mathrm{O}_{4}-\mathrm{ReF}-\mathrm{NTS}$ ); (b) magnetization of $\mathrm{Fe}_{3} \mathrm{O}_{4}-\mathrm{ReF}-\mathrm{NTS}$ measured at 5 and $300 \mathrm{~K}$. The inset image shows that the $\mathrm{Fe}_{3} \mathrm{O}_{4}-$ ReF-NTs can be separated by an applied magnetic field

remanence, and the initial slopes of the magnetization curve are steep. These observations are related to finite-size and surface effects [46]. At $5 \mathrm{~K}$, the $\mathrm{Fe}_{3} \mathrm{O}_{4}$ -ReF-NTs exhibit ferromagnetic characteristics, including saturation magnetization $\left(M_{\mathrm{s}}=32.4\right.$ emu $/ \mathrm{g})$, coercivity $\left(H_{\mathrm{c}}=150.1 \mathrm{Oe}\right)$, and remanence $\left(M_{\mathrm{r}}=6.3 \mathrm{emu} / \mathrm{g}\right)$. These are roughly comparable to the corresponding data for the $\mathrm{Fe}_{3} \mathrm{O}_{4}$ nanocrystal sample itself, implying that the magnetic properties are not affected during the assembly process. The saturation magnetization value of the $\mathrm{Fe}_{3} \mathrm{O}_{4}-\mathrm{ReF}-\mathrm{NTs}$ is even higher than that for $\mathrm{SiO}_{2} / \mathrm{Fe}_{3} \mathrm{O}_{4}$ nanocrystals core/shell spheres [47], because of the diamagnetic contribution of the thick silica shell in the latter case. 
The excellent magnetic properties should allow the nanotubes to be used in biomedical applications. The magnetic separability of the magnetic nanotube composites was tested in hexane (Fig. 8(b) inset); the black particles were attracted to a magnet within a short time.

\section{Conclusions}

Ordered rare earth fluoride nanotube (ReFNT) arrays and uniform dispersed magnetitedoped $\mathrm{Fe}_{3} \mathrm{O}_{4}-$ ReF-NTs possessing excellent UC fluorescence and magnetic properties have been successfully obtained by using a nanocrystal assembly approach on AAO membranes. The nanocrystal colloidal self-assembly and spreading processes confined in the AAO nanochannels are simple and versatile and allow the preparation of tubular structures with diameters ranging from tens of nanometers to micrometers. TEM images show that the nanotubes are composed of close-packed uniform nanocrystals. The wall thickness can be varied from 10 to $35 \mathrm{~nm}$ by simply increasing the concentration of nanocrystals from 0.02 to $0.4 \mathrm{mmol} / \mathrm{L}$, while the morphology of the nanotube walls changes from small isolated domain structures to percolating and even compact domains with increasing concentration. According to the experimental results and quantitative predictions, the organic oleic acid groups capping the nanocrystals easily spread on the internal surface of the AAO template and selfassemble into a tubular structure directed within the nanochannels of the templates. Excellent UC luminescence of $\alpha-\mathrm{NaYF}_{4}: 20 \% \mathrm{Yb}^{3+} / 2 \% \mathrm{Er}^{3+}$ and $\alpha-\mathrm{NaYF}_{4}: 20 \% \mathrm{Yb}^{3+} / 2 \% \mathrm{Tm}^{3+}$ nanotubes under infrared excitation is realized. The nanotubes show a high emission ratio of red to green photons, because of the composition of the nanosized rare earth fluoride crystals. Magnetic measurements of the multifunctional nanotubes composed of $\alpha$ $-\mathrm{NaYF}_{4}: 20 \% \mathrm{Yb}^{3+} / 2 \% \mathrm{Er}^{3+}$ and $\mathrm{Fe}_{3} \mathrm{O}_{4}$ nanocrystals show strong superparamagnetic properties, which are comparable to those of the aggregated $\mathrm{Fe}_{3} \mathrm{O}_{4}$ nanocrystals, suggesting that the magnetic properties are not affected during the assembly process.

\section{Acknowledgements}

This work was supported by the National Science Foundation of China (20721063, 20890123, and 20521140450), the State Key Basic Research Program of the China (2006CB932302), Sci. \& Tech. Commission of Shanghai Municipality (08DZ2270500) and Shanghai Leading Academic Discipline Project (B108).

\section{References}

[1] Xia, Y. N.; Yang, P. D.; Sun, Y. G.; Wu, Y. Y.; Brian, M.; Byron, G.; Yin, Y. D.; Franklin, K.; Yan, H. Q. Onedimensional nanostructures: Synthesis, characterization, and applications. Adv. Mater. 2003, 15, 353-389.

[2] Wang, X. D.; Song, J. H.; Wang, Z. L. Nanowire and nanobelt arrays of zinc oxide from synthesis to properties and to novel devices. J. Mater. Chem. 2007, 17, 711720.

[3] Huang, M. H.; Mao, S.; Feick, H.; Yan, H. Q.; Wu, Y. Y.; Kind, H.; Weber, E.; Russo, R.; Yang, P. D. Roomtemperature ultraviolet nanowire nanolasers. Science 2001, 292, 1897-1899.

[4] Rumbles, G. Solid-state optics: A laser that turns down the heat. Nature 2001, 409, 572-573.

[5] Downing, E.; Hesselink, L.; Ralston, J.; Macfarlane, R. A three-color, solid-state, three-dimensional display. Science 1996, 273, 1185-1189.

[6] Law, M.; Greene, L. E.; Johnson, J.; Saykally, C. R.; Yang, P. D. Nanowire dye-sensitized solar cells. Nat. Mater. 2005, 4, 455-458.

[7] van de Rijke, F.; Zijlmans, H.; Li, S.; Vail, T.; Raap, A. K. Up-converting phosphor reporters for nucleic acid microarrays. Nat. Biotech. 2001, 19, 273-276.

[8] Giesber, H.; Ballato, J.; Chumanov, G.; Kolis, J.; Dejneka, M. Spectroscopic properties of $\mathrm{Er}^{3+}$ and $\mathrm{Eu}^{3+}$-doped acentric $\mathrm{LaBO}_{3}$ and $\mathrm{GdBO}_{3}$. J. Appl. Phys. 2003, 93, 8987 $-8991$.

[9] Wang, X.; Zhuang, J.; Peng, Q.; Li, Y. D. A general strategy for nanocrystal synthesis. Nature 2005, 437, 121-124.

[10] Yi, G. S.; Lu, H. C.; Zhao, S. Y.; Ge Y.; Yang, W. J.; Chen, D. P.; Guo, L. H. Synthesis, characterization, and biological application of size-controlled nanocrystalline $\mathrm{NaYF}_{4}: \mathrm{Yb}$, Er infrared-to-visible up-conversion phosphors. 
Nano Lett. 2004, 4, 2191-2196.

[11] Heer, S.; Kompe, K.; Gudel, H. U.; Haase, M. Highly efficient multicolour upconversion emission in transparent colloids of lanthanide-doped $\mathrm{NaYF}_{4}$ nanocrystals. Adv. Mater. 2004, 16, 2102-2105.

[12] Mai, H. X.; Zhang, Y. W.; Si, R.; Yan, Z. G.; Sun, L. D.; You, L. P.; Yan, C. H. High-quality sodium rare-earth fluoride nanocrystals: Controlled synthesis and optical properties. J. Am. Chem. Soc. 2006, 128, 6426-6436.

[13] Boyer, J. C.; Vetrone, F.; Cuccia, L. A.; Capobianco, J. A. Synthesis of colloidal upconverting $\mathrm{NaYF}_{4}$ nanocrystals doped with $\mathrm{Er}^{3+}, \mathrm{Yb}^{3+}$ and $\mathrm{Tm}^{3+}, \mathrm{Yb}^{3+}$ via thermal decomposition of lanthanide trifluoroacetate precursors. J. Am. Chem. Soc. 2006, 128, 7444-7445.

[14] Zhang, F.; Wan, Y.; Ying, T.; Zhang, F. Q.; Shi, Y. F.; Xie, S. H.; Li, Y. G.; Xu, L.; Tu, B.; Zhao, D. Y. Uniform nanostructured arrays of sodium rare-earth fluorides for highly efficient multicolor upconversion luminescence. Angew. Chem. Int. Ed. 2007, 46, 7976-7979.

[15] Zhang, F.; Wan, Y.; Shi, Y. F.; Tu, B.; Zhao, D. Y. Ordered mesostructured rare-earth fluoride nanowire arrays with upconversion fluorescence. Chem. Mater. 2007, 20, 3778-3784.

[16] Greene, L. E.; Law, M.; Goldberger, J.; Kim, F.; Johnson, J. C.; Zhang, Y. F.; Saykally, R. J.; Yang, P. D. Lowtemperature wafer-scale production of $\mathrm{ZnO}$ nanowire arrays. Angew. Chem. Int. Ed. 2003, 42, 3031-3034.

[17] Vayssieres, L.; Keis, K.; Lindquist, S. E.; Hagfeldt, A. Purpose-built anisotropic metal oxide material: 3D highly oriented microrod array of ZnO. J. Phys. Chem. B 2001, 105, 3350-3352.

[18] Goldberger, J.; He, R. R.; Zhang, Y. F.; Lee, S. K.; Yan, H. Q.; Choi, H. J.; Yang, P. D. Single-crystal gallium nitride nanotubes. Nature 2003, 422, 599-602.

[19] Vayssieres, L. Growth of arrayed nanorods and nanowires of ZnO from aqueous solutions. Adv. Mater. 2003, 15, 464-466.

[20] Murray, C. B.; Kagan, C. R.; Bawendi, M. G. Selfassembly of a two-dimensional superlattice of molecularly linked metal clusters. Science 1996, 273, 1690-1693.

[21] Alivisators, A. P. Semiconductor clusters, nanocrystals, and quantum dots. Science 1996, 271, 933-937.

[22] Shi, J.; Gider, S.; Babcock, K.; Awschalom, D. D. Magnetic clusters in molecular beams, metals, and semiconductors. Science 1996, 271, 937-941.
[23] Kagan, C. R.; Murry, C. B.; Nirmal, M.; Bawendi, M. G. Electronic energy transfer in CdSe quantum dot solids. Phys. Rev. Lett. 1996, 76, 1517-1520.

[24] Harfenist, S. A.; Wang, Z. L.; Alvarez, M. A.; Vezmar, I.; Whetten, R. L. Highly oriented molecular Ag nanocrystal arrays. J. Phys. Chem. 1996, 100, 13904-13910.

[25] Zhang, F.; Zhao, D. Y. Synthesis of uniform rare earth fluoride $\left(\mathrm{NaMF}_{4}\right)$ nanotubes by in situ ion-exchange from their hydroxide $\left[\mathrm{M}(\mathrm{OH})_{3}\right]$ parents. ACS Nano, 2009, 3, 159-164.

[26] Zhou, Y. K.; Li, H. L. Sol-gel template synthesis and structural properties of a highly ordered $\mathrm{LiNi}_{0.5} \mathrm{Mn}_{0.5} \mathrm{O}_{2}$ nanowire array. J. Mater. Chem. 2002, 12, 681-686.

[27] Son, S. J.; Reichel, J.; He, B.; Schuchman, M.; Lee, S. B. Magnetic nanotubes for magnetic-field-assisted bioseparation, biointeraction, and drug delivery. J. Am. Chem. Soc. 2005, 127, 7316-7317.

[28] Rabin, O.; Herz, P. R.; Lin, Y. M.; Akinwande, A. I.; Cronin, S. B.; Dresselhaus, M. S. Formation of thick porous anodic alumina films and nanowire arrays on silicon wafers and glass. Adv. Funct. Mater. 2003, 13, 631-638.

[29] Steinhart, M.; Wehrspohn, R. B.; Gosele, U.; Wendorff, J. $\mathrm{H}$. Nanotubes by template wetting: A modular assembly system. Angew. Chem. Int. Ed. 2004, 43, 1334-1340.

[30] Lakshmi, B. B.; Dorhout, P. K.; Martin, C. R. Sol-gel template synthesis of semiconductor nanostructures. Chem. Mater. 1997, 9, 857-862.

[31] Giersig, M.; Mulvaney, P. Preparation of ordered colloid monolayers by electrophoretic deposition. Langmuir 1993, 9, 3408-3413.

[32] Motte, L.; Billoudet, F.; Lacaze, E.; Douin, J.; Pileni, M. P. Self-organization into 2D and 3D superlattices of nanosized particles differing by their size. J. Phys. Chem. B 1997, 101, 138-144.

[33] Korgel, B. A.; Fitzmaurice, D. Condensation of ordered nanocrystal thin films. Phys. Rev. Lett. 1998, 80, 35313534.

[34] Lin, X. M.; Jaeger, H. M.; Sorensen, C. M.; Klabunde, K. J. Formation of long-range-ordered nanocrystal superlattices on silicon nitride substrates. J. Phys. Chem. B 2001, 105, 3353-3357.

[35] de Gennes, P. G. Wetting: Statics and dynamics. Rev. Mod. Phys. 1985, 57, 827-863.

[36] Isrealachvili, J. N. Intermolecular and Surface Forces; Academic Press: New York, 1992. 
[37] Hamaker, H. C. The London-van der Waals attraction between spherical particles. Physica IV 1937, 10581072.

[38] Stouwdam, J. W.; van Veggel, Frank C. J. M. Nearinfrared emission of redispersible $\mathrm{Er}^{3+}, \mathrm{Nd}^{3+}$, and $\mathrm{HO}^{3+}$ doped $\mathrm{LaF}_{3}$ nanoparticles. Nano Lett. 2002, 2, 733737.

[39] Sivakumar, S.; Diamente, P. R.; van Veggel, Frank, C. J. M. Silica-coated $\mathrm{Ln}^{3+}$-doped $\mathrm{LaF}_{3}$ nanoparticles as robust down- and upconverting biolabels. Chem. Eur. J. 2006, $12,5878-5884$.

[40] Menyuk, N.; Dwight, K.; Pierce, J. W. NaYF 4 : Yb, Er-An efficient upconversion phosphor. Appl. Phys. Lett. 1972, 21, 159-161.

[41] Page, R. H.; Schaffers, K. I.; Waide, P. A.; Tassano, J. B.; Payne, S. A.; Krupke, W. F.; Bischel, W. K. Upconversionpumped luminescence efficiency of rare-earth-doped hosts sensitized with trivalent ytterbium. J. Opt. Soc. Am. B 1998, 15, 996-1008.

[42] Krämer, K. W.; Biner, D.; Frei, G.; Güdel, H. U.; Hehlen, M. P.; Lüthi, S. R. Hexagonal sodium yttrium fluoride-based green and blue emitting upconversion phosphors. Chem.
Mater. 2004, 16, 1244-1251.

[43] Bai, X.; Song, H. W.; Pan, G. H.; Lei, Y. Q.; Wang, T.; Ren, X.G.; Lu, S. Z.; Dong, B.; Dai, Q. L.; Fan, L. B. Sizedependent upconversion luminescence in $\mathrm{Er}^{3+} / \mathrm{Yb}^{3+}$ codoped nanocrystalline yttria: Saturation and thermal effects. J. Phys. Chem. C 2007, 111, 13611-13617.

[44] Lee, J. W.; Jin, S. M.; Hwang, Y. S.; Park, J. G.; Park, H. M.; Hyeon, T. Simple synthesis of mesoporous carbon with magnetic nanoparticles embedded in carbon rods. Carbon 2005, 43, 2536-2543.

[45] Woo, K. J.; Hong, J. W.; Choi, S. M.; Lee, H. W.; Ahn, J. P.; Kim, C. S.; Lee, S. W. Easy synthesis and magnetic properties of iron oxide nanoparticles. Chem. Mater. 2004, 16, 2814-2818.

[46] Kang, E.; Park, J. N.; Hwang, Y. S.; Kang, M. S.; Park, J. G.; Hyeon, T. Direct synthesis of highly crystalline and monodisperse manganese ferrite nanocrystals. J. Phys. Chem. B 2004, 108, 13932-13935.

[47] Yi, D. K.; Selvan, S. T.; Lee, S. S.; Papaefthymiou, G. C.; Kundaliya, D.; Ying, J. Y. Silica-coated nanocomposites of magnetic nanoparticles and quantum dots. J. Am. Chem. Soc. 2005, 127, 4990-4991. 